\title{
Feeding the economics of obesity in the EU in a healthy way
}

\author{
Fernando Antonanzas • Roberto Rodríguez
}

Published online: 6 June 2010

(C) Springer-Verlag 2010

Obesity and overweight (body mass index (BMI) $>30$ and BMI between 25 and 30, respectively, calculated as the ratio between weight in kilograms and the square of height measured in centimetres) are considered by many epidemiologists as the new pandemic in developed countries. At the EU, this pandemic has a prevalence of around $50 \%$ for those aged 50 and older, being in the range 20-30\% for total population in most of the member states (MS). Further, children's prevalence has grown during the last 20 years being also in a similar range to the figures of the adults. The trends are positive in almost all the MS with the exception of the Scandinavian countries where the trends are more stable and the prevalence rates are lower than in the other countries. Life-styles, mainly, sedentary and high intake of calories derived from products containing intense doses of energy-dense elements such as fats and sugar together with the greater amount of food intake are the major responsible for the obesity positive trends. Genetics are believed to only account for a marginal $1 \%$ of the cases $[1,2]$.

Health consequences of obesity have also been frequently studied, and the list of related conditions keeps growing (type 2 diabetes, hypertension, cardiovascular diseases, some cancers, gallbladder disease, osteoarthritis, disabilities, psychosocial problems, etc). These diseases are mostly chronic, their trends, again, are positive, and the final result is a lower life expectancy, estimated around 9 years less on average. Obesity may also change the forecasts of future trends of life expectancy curbing them to lower figures than they would have otherwise occurred [3].

F. Antonanzas $(\bowtie) \cdot R$. Rodríguez

Department of Economics, University of La Rioja,

26004 Logrono, Spain

e-mail: fernando.antonanzas@unirioja.es
However, some studies show counterintuitive results in the sense that obesity is not as highly associated with mortality among the elderly as it is at young ages and may even be associated with longer survival among the elderly [4].

Disability is also an immediate consequence. Some authors [5] calculated that increasing prevalence of obesity explains about $40 \%$ of the contribution of chronic diseases to the rise in disability rates between 1986 and 1994 . Functional impairment (unable to walk a quarter-mile, climb 10 steps, to pick up a 10-lb weight and to bend over) is also more likely among obese adults ages 60 and over.

Individual versus society responsibility of this pandemic disease has been widely discussed, and probably, as in other situations, both sides share a part. Of course, individuals have the last word to eat/not to eat a certain number of calories and to exercise or not, but as US General Surgeon stated in 2001, the absence of accessible places to play and streets to walk, the provision of healthy and appealing food choices in school lunchrooms and office cafeterias, the education of expectant mothers on the benefits of breast-feeding and the requirement of daily physical education in our schools is a community responsibility.

The economics related to obesity have focused on several issues to highlight the costs to both health systems and society as a whole. A review by Müller [2] showed that at the EU, reported relative burdens ranged from 0.09 to $0.61 \%$ of each country's gross domestic product. When only health care costs were calculated and related to the total health care expenditures, country rates are up to $8 \%$ [6]. However, the methodologies of the studies are not homogeneous, and many differences in values and rates may be explained by the way studies were developed.

There is no doubt that obesity has significant health care costs associated with its treatments and its direct consequences. Absence from work due to health-related 
problems reduces productivity, and premature mortality reduces the national output relative to the level that would have been otherwise achieved [7]. All things being equal, chronic conditions associated with obesity may increase the public and private costs of health care for the elderly. Calculations differ depending on the methodology, on the rate of discount and on the time horizon among other factors, but results are conclusive.

However, the economic studies are not unambiguous when they analyse the lifetime costs of obesity. For instance, Lakdawalla [8] assessed whether reduced longevity among obese would offset the increased health care costs for Medicare finding that because obese 70-year-olds live about as long as those with normal weight, increased Medicare costs were not offset by shorter lives. Some statistical and epidemiological effects may interact with these calculations and bias the results; hence, there is a necessity for standardisation of cost calculations so that a more precise knowledge of the situation can be obtained.

Rappange [9] estimated for the Netherlands the lifetime drug expenditures of two groups of persons obese and "healthy living" and found that were higher for the former one. Furthermore, obesity prevention results in savings on drugs for obesity-related diseases until the age of 74 years, which offset additional drug costs for diseases unrelated to obesity in life-years gained. Other health care costs such as long-term care will increase substantially, while savings in other health care segments are small or non-existent.

Some experts suggest that modified foods (for instance, altered omega 3 fatty acid content of some foods as milk and meat) will improve heart health. That will mean a change in diet with some consequences in survival. However, if lifestyles-sedentarism and greater intake of food than needed-are not changed, obesity will still be present in societies what will also have implications, perhaps not so large in survival terms as those exclusively derived from standard food but still some disabilities closely related to that condition.

Having all these elements in mind, many agents have advocated for government intervention. However, from a pure economic point of view, as McCormick [7] highlights, such an intervention would be fully justified on the grounds of equity promotion (e.g. if there were some lack of equity in health care to obese persons), of upholding the law and of correcting market failures. If we fix our attention on the more related issues to economics, i.e. market failures, we can distinguish several factors: externalities, imperfect information, demerit goods and time-inconsistent preferences.

In these four fields, there are controversial results, and therefore, different opinions among researchers and politicians. For instance, higher health care costs of obese persons borne by society would be a clear externality but, so far, economic results are not conclusive with respect to whether the lifetime health care costs of an obese are greater than those of a normal weight person. Imperfect information may take place on different ways, and it would require an effort to clearly identify the sources and causes to correct them (labels on food packages, risks about obesity, life-styles education, etc), but, again, this identification process needs to be improved so that public intervention goals are better adjusted. Imperfect information is related to risk perception what in fact is one of the major drivers of behavioural change. Probably, government intervention in preventing obesity would be more justified when this imperfect information is related to children, in the sense that they are more vulnerable to other pressures from the industry through commercial campaigns and because a healthy life style may be considered as a longterm investment. In addition to all these fields, individuals may behave in such a way as if they had time-inconsistent preferences. There may be several reasons for that such as the addictive attraction to some foods but, once more, it is hard to identify the goals where government intervention would be backed up on economic grounds.

There is an important research opportunity for economics in this area. As it has been highlighted [5], individual's food consumption and physical activity choices, effects of lower prices in food as determinants of obesity, economic explanation for rising trends in obesity and differences across countries, costs of health care for obesityrelated conditions, public policy questions of whether governments should intervene to reduce the social cost of obesity and efficiency studies of medical and public health interventions of reducing obesity are major issues that have already been addressed but that still remain quite open for further analysis.

As a concluding remark, obesity is a major public health issue in the $\mathrm{EU}$, probably not receiving so much attention as needed, it has clear economic implications in annual health budgets and productivity, and it requires more complete analysis in several fields so that a better informed discussion can be carried out to justify government interventions. In conclusion, an interesting field to do research.

\section{References}

1. Müller-Riemenschneider, F., Reinhold, T., Berhöfer, A., Willich, S.N.: Health-economic burden of obesity in Europe. Eur. J. Epidemiol. 23, 499-509 (2008)

2. International Obesity TaskForce. Obesity in Europe. Web: http://www.iotf.org

3. Olshansky, S.J., et al.: A potential decline in life expectancy in the United States in the 21st century. NEJM 352(11), 1138-1142 (2005)

4. Today's Research on Aging: Population Reference Bureau, no 13, 2008 
5. Bhattacharya, J., Choudhry, K., Lakdawalla, D.: Chronic disease and severe disability among working-age populations. Med. Care 46(1), 92-100 (2008)

6. Phillipson, T., Postner, R.: Is the obesity epidemic a public health problem? A decade of research on the economics of obesity. NBER Working Paper 14010 (2008)

7. McCormick, B., Stone, I., Corporate analytical team: Economic costs of obesity and the case for government intervention. Obes. Rev. 8(1), 161-164 (2007)
8. Lakdawalla, D.N., Goldman, D.P., Shang, B.: The health and cost consequences of obesity among the future elderly. Health Aff. 24(2), w5r30-w5r41 (2005)

9. Rappange, D.R., Brouwer, W.B.F., Hoogenveen, R.T., Van Baal, P.H.M.: Health care costs and obesity prevention. Pharmacoeconomics 27(12), 1031-1044 (2009) 